\title{
APPLICATION OF TERRASAR-X DATA TO THE MONITORING OF URBAN SUBSIDENCE IN THE CITY OF MURCIA
}

\author{
Daniel Monells ${ }^{(I)}$, Giuseppe Centolanza ${ }^{(l)}$, Jordi J. Mallorqui ${ }^{(I)}$, Sergi Duque ${ }^{(I)}$, Paco López-Dekker ${ }^{(1,4)}$, \\ Roberto Tomás ${ }^{(2)}$, Gerardo Herrera ${ }^{(3)}$, Juan M. López-Sánchez ${ }^{(2)}$, Fernando Vicente ${ }^{(2)}$, \\ Victor D. Navarro-Sanchez ${ }^{(2)}$, Joaquín Mulas ${ }^{(3)}$
}

(1) Remote Sensing Lab.-UPC, Spain; (2) Universidad de Alicante (UA), Spain; (3) Instituto Geológico y Minero (IGME), Spain; (4) DLR, Germany

\begin{abstract}
This paper presents an analysis of the performance of TerraSAR-X for subsidence monitoring in urban areas. The city of Murcia has been selected as a test-site due to its high deformation rate and the set of extensometers deployed along the city that provide validation data. The obtained results have been compared with those ob-tained from ERS/ENVISAT data belonging to the same period and validated with the in-situ measurements.
\end{abstract}

Index Terms - Differential, Interferometry, Subsidence, Monitoring

\section{INTRODUCTION}

Orbital DInSAR is a technique widely used to survey the surface of the Earth and monitor hazards due to natural and human agents, such as earthquakes or mining [1][2][3]. Nowadays, there are a large number of satellites in orbit carrying SAR instruments able to perform this monitoring. In this work we will make a comparison of the results of urban subsidence moni-toring obtained using data from veteran satellites ERS-2 and ENVISAT and the new satellite TerraSAR-X. The objective of the paper is to compare the performance of each system under different aspects, such as the management and detection of different kinds of targets (distributed or deterministic), the preservation of the coherence/phase stability and its temporal evolution, and a comparison of the de-formation results using each set of data.

\footnotetext{
This work has been supported by the Spanish MICINN and European Union FEDER funds under project TEC2008-06764-C02. The TerraSAR-X images were provided by DLR in the framework of the scientific project GEO0389. ERS and ENVISAT data were provided by ESA in the framework of the CAT1 1 project 2494. The Cartographical Service of Murcia (CARTOMUR) has provided the DEM and orto-images used in this work.
}

\section{THE COHERENT PIXELS TECHNIQUE (CPT)}

The Coherent Pixels Technique has been widely used for monitoring urban subsidence [3]. The algorithm can use both coherence and amplitude stability criteria to perform pixels selection. The former is more suited for detecting stable distributed targets and the latter for detecting the socalled Permanent Scatterers (PS). The retrieval of the deformation time-series is done in two steps. Firstly, a linear model adjustment to data provides the linear velocity of deformation, the DEM error and the azimuth position of the PS (only for amplitude-based processing when large Dopplers are present). Secondly, the non-linear processing retrieves the non-linear deformation and the atmospheric phase screen for each image.

\section{THE CITY OF MURCIA TEST-SITE}

Subsidence has occurred in the metropolitan area of Murcia City (SE Spain) as a result of soil consolidation due to piezometric level depletion caused by excessive pumping of groundwater. The study area is part of Segura River valley located in the oriental sector of the Betic Cordillera. Permian and Triassic deformed materials corresponding to the Internal Zones of the Betic Cordillera make up the basement. The basin filling comprises Upper Miocene to Quaternary sediment fluvial deposits. Younger sediments are highly compressible and the most problematic from a geotechnical point of view [4]. They constitute an aquifer system that is divided in two units. The superficial aquifer reaches 30 meters below the surface, and it is formed by recent clay, silt and sands facies. The deep aquifer, located below, is composed of a sequence of gravels and sands alternating with confined silt and clay layers. Subsidence is triggered by the excessive water pumping of the first layer of deep aquifer. In fact a piezometric level decline between 5 and $15 \mathrm{~m}$ was measured on this layer during recent drought periods: 1980-1983, 1993-1995 and 2005-2008. After the second drought period, ground subsidence was triggered causing damages in buildings and other structures with an estimated cost of 50 million Euros, generating a 
significant social impact. As a consequence, a permanent monitoring has been carried out since then, by using an extensometer network since 2001 and also through the application of different PSI [5]. Figure 1 shows the distribution of the compressible thickness and the maximum ground-water depletion in the period 2004-2008 and the wells distributed along the city.

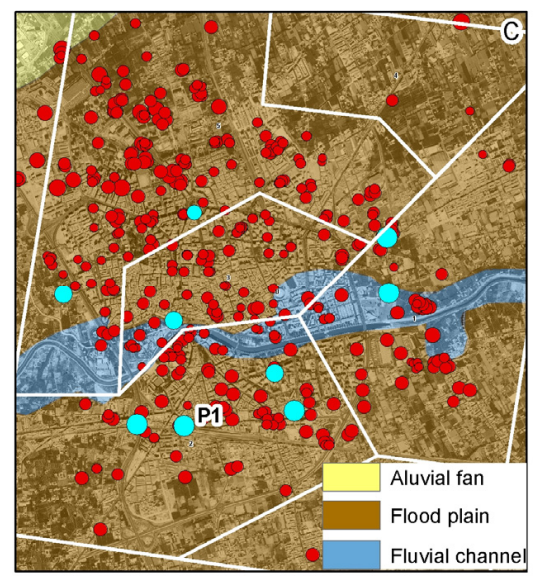

(a)

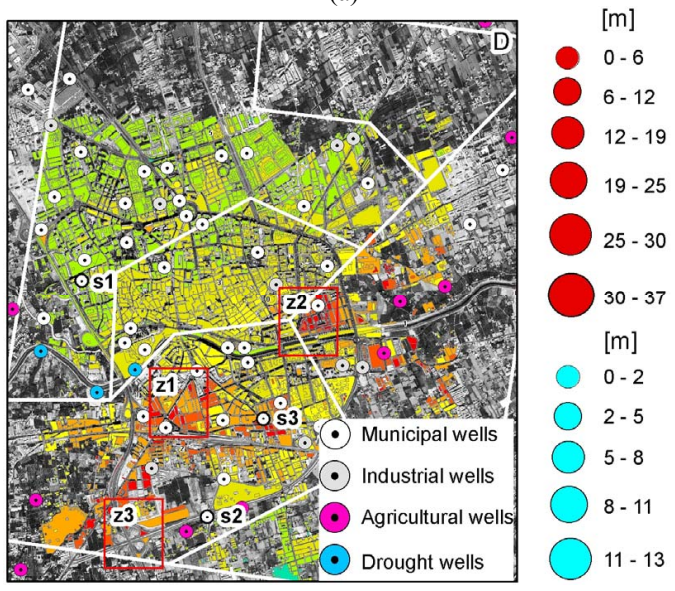

(b)

Figure 1 (a) Geology with superposition of the distribution of the compressible thickness (red circles) and the maximum groundwater depletion in the period 2004-2008 (blue circles). (b) Subsidence rate measured from TerraSAR-X dataset interpolated for every building block of the city and location of the different types of wells

\section{TERRASAR-X DATASET}

The results presented in this work have been obtained with 51 TerraSAR-X images acquired during the temporal interval comprised from $06 / 28 / 2008$ to $04 / 06 / 2010$. The selection of interferograms has been done with a Delauney triangulation. The maximum temporal baseline used has been 176 days and the maximum spatial baseline 167 meters. 137 interferograms have been generated.
In the processing different types of pixel selection methods have been used, such as coherence or amplitude stability. The larger resolution of TerraSAR images allows working with smaller coherence windows if compared, for instance, with ERS or ENVISAT data. As expected, TerraSAR-X data preserves very well the coherence on urban areas but, at the same time, it suffers of a fast decorrelation on non-urban ones. This coherence behavior is clearly shown in Figure 2. Figure 2 (a) shows a coherence map calculated with a $5 \times 5$ averaging window (equivalent to 12 looks) for an 11 days interferogram. The coherence map clearly distinguishes the urban areas from the non-urban ones. Figure 2 (b) shows the coherence histograms for three interferograms with temporal baselines of 55, 242 and 429 days respectively. There is just a small shift of the maximum towards lower coherences when the temporal baseline is increased. For the two interferograms with the larger temporal spans both histograms are almost identical.

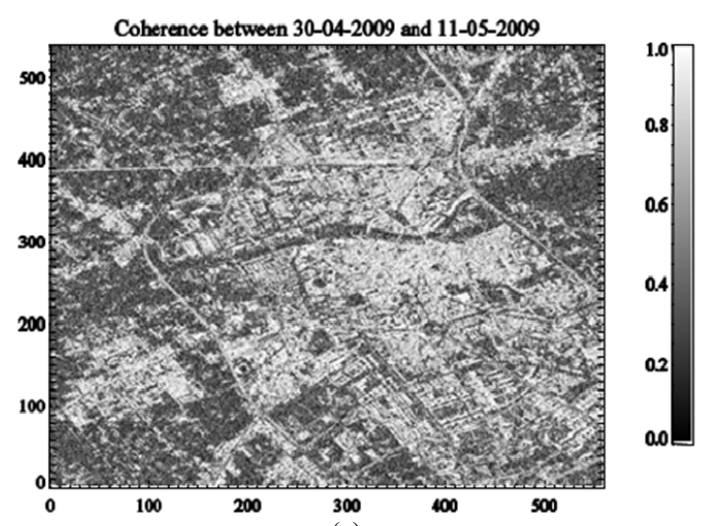

(a)

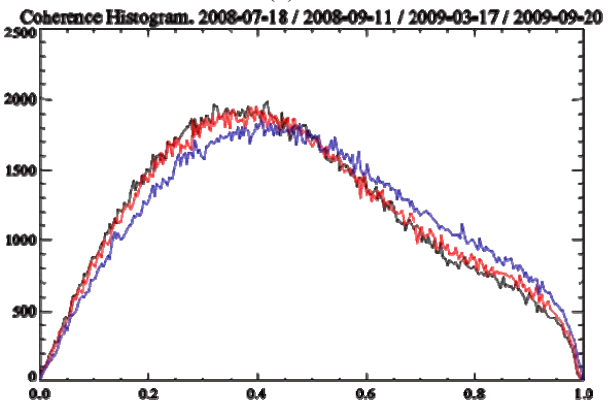

(b)

Figure 2 (a) $5 \times 5$ coherence map for a 11 days baseline (b) Coherence histogram for 55 (blue), 242 (red) and 429 (black) days baselines.

\section{DEFORMATION RESULTS}

The deformation results obtained are shown in Figure 3. The general patterns of deformation are correctly retrieved but the degree of detail, reaching building level, shows the main advantage of high resolution data for urban subsidence monitoring. 


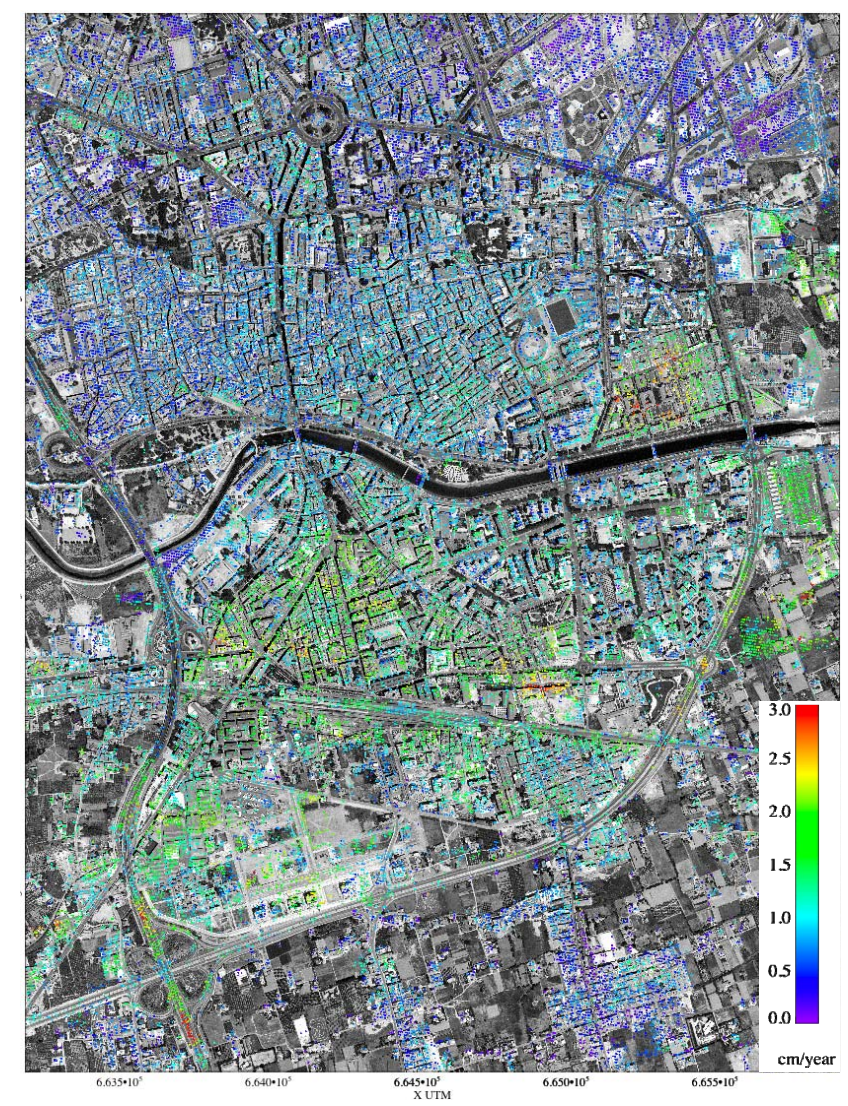

Figure 3 Linear velocity retrieved for Murcia test-site using TerraSAR-X.

Figure 3 shows a good correlation of the measured deformations and the distribution of triggering factor shown in Figure 1. Deformations are located in those regions were the depletion of the groundwater was stronger and the compressible thickness of the terrain. Stronger deformations are located South and North-East of the Segura River. In addition to the overall deformation pattern different subsidence gradients can be perfectly seen in the results. Those are the most dangerous for the buildings and civil infrastructures. Different examples of differential settlement intensified by the different types of foundations have been found along the city. X-band data has been able to reveal that many buildings are subsiding at rates different to those at ground-level. This can be explained by the foundation of those buildings, which are constituted by deep piles that are less affected by subsidence. In-situ pictures have confirmed the obtained results.

An interesting example of the excellent performance of TerraSAR-X for monitoring civil infrastructures can be seen in Figure 4. The deformation is detected on the access ramps of the bridge, which do not have such strong and deep foundations as the bridge over the highway. The piles of the bridge make this part of the structure less susceptible to experiment settlements, and hence measured deformation on the bridge is below $5 \mathrm{~mm} /$ year, which is the lowest value along it. This phenomenon is a common problem due to the construction technique employed.

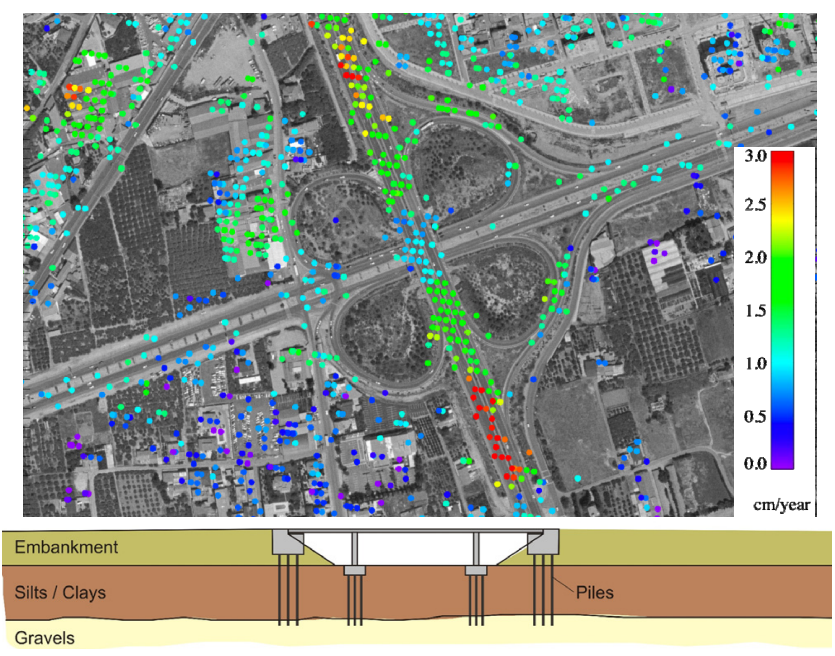

Figure 4 Detail of the bridge over the highway. The deformation on the access ramps is clearly visible while the bridge itself is perfectly stable as seen in the deformation profile along the bridge.

\section{DEM REFINEMENT}

One of the side-products of the DInSAR processing is the DEM error of the pixels. The DTM used to generate the differential interferograms does not consider the presence of buildings. The updated height is used to perform a better geolocation of the results that allows precisely determine if a particular pixel is located at ground-level or on top of a building. Figure 5 shows the height error obtained in the city center.

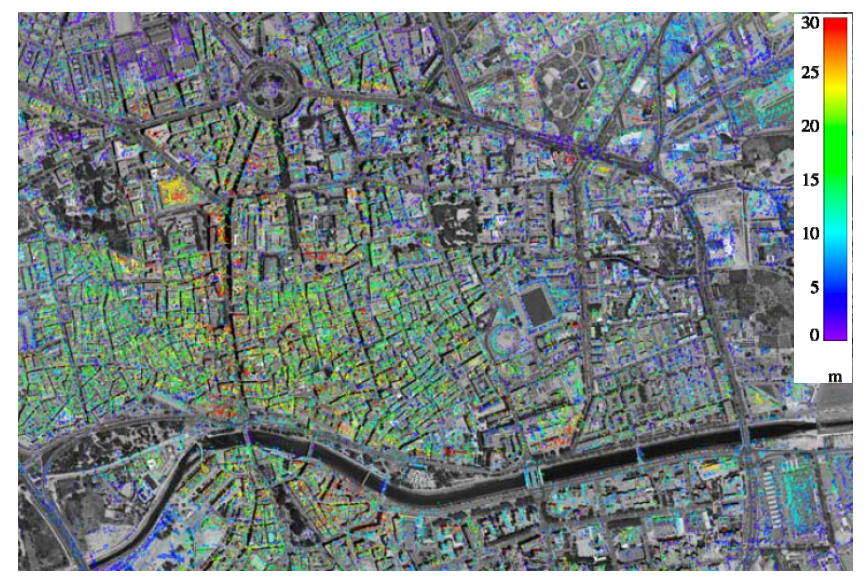

Figure 5 Retrieved height error in the city. Higher errors are located along the main streets of the city where taller buildings are located. 


\section{RESULTS VALIDATION}

The deformation results, both linear velocity and time-series are being validated by IGME. As a preliminary result, in Figure 6 it is shown the cumulated deformation of three representative extensometers and the surrounding pixels in a colour scale with a $1 \mathrm{~mm}$ step. In order to estimate the error between both datasets, it has been calculated the average and standard deviation of the absolute difference of the subsidence rate measured in all the pixels included within a radius of 15,30 and $60 \mathrm{~m}$ with respect to each extensometer. Results are summarized in Figure 6, observing that the average error of extensometers S2 and S3 is $39 \%$ and $15 \%$ of measured deformation for any chosen radius. Note that in the case of S2, those pixels located on the ground can be easily distinguished from those located on the buildings nearby. Therefore ground deformation measurements of these pixels are more representative to the deformation measured by the extensometer. In fact if we select a radius smaller than $30 \mathrm{~m}$, the pixels associated to the buildings are not selected, and the error is improved to $18 \%$ of measured deformation. Therefore, even though measured subsidence is small and a validation experiment cannot be performed, X-band measurements are capable of detecting sensible sub-centimetric deformations of the ground surface

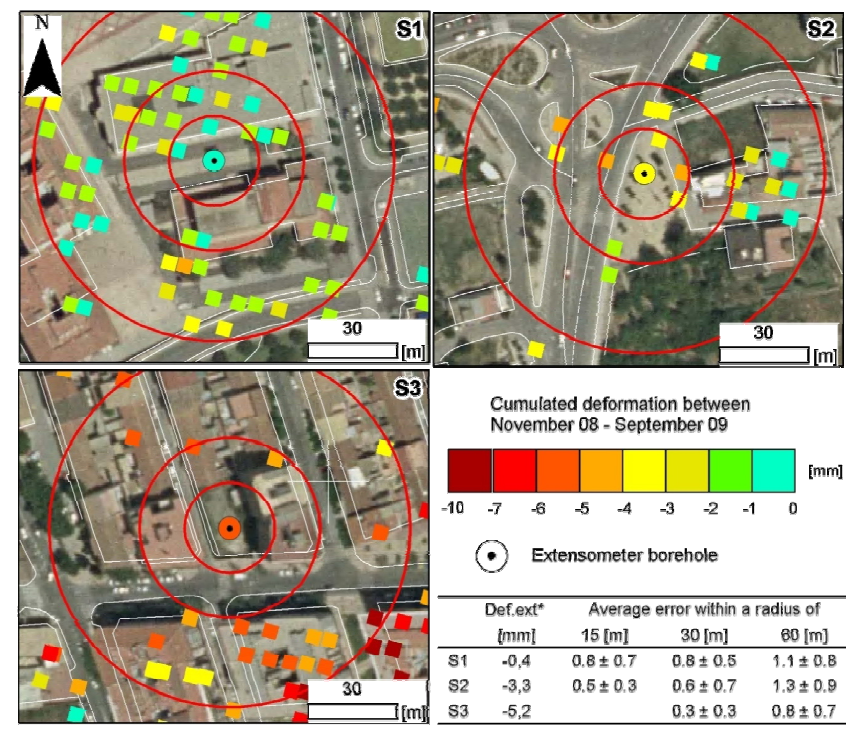

Figure 6 Cumulated deformation between November 2008 and September 2009 measured by the X-band dataset and the extensometer network.

\section{CONCLUSIONS}

The Coherent Pixel Technique (CPT) has been successfully used to detect and monitor recent subsidence affecting Murcia city by exploiting TerraSAR-X data. The X-band data yielded a much denser measurement point distribution but a lower spatial coverage, being more adequate for local deformation phenomena analysis than the C-band, especially if we consider the higher cost of the SAR images of the former. The comparison of X-band and extensometer measurements indicates their capability for detecting sensible variations of small ground surface deformations.

The spatial analysis of X-band measured subsidence has permitted to demonstrate that settlement areas are located within the flood plain of the valley close to the River Segura where: the soft soil is thicker, the maximum piezometric decline has occurred; and the agricultural and drought pumping wells are located. The comparison of Xband displacement time series with the piezometric temporal evolution has permitted to demonstrate that the 11 days temporal sampling of the X-band dataset permits to detect seasonal variations of ground surface displacement that cannot be detected, for instance, with the C-band data.

Finally one example of ground surface deformation analysis in infrastructures has been presented. This example illustrates that the X-band spatial resolution permits to identify the differential settlement caused when the foundations of buildings and infrastructures off different types are joined, such as the settlement mechanisms governing the different parts of the highway bridge.

\section{REFERENCES}

[1] Ferretti, A., C. Prati, Rocca, F. (2000). Nonlinear subsidence rate estimation using permanent scatterers in differential SAR interferometry. IEEE Transactions on Geoscience and Remote Sensing, 38, 2202-2212

[2] Berardino, P., Fornaro, G., Lanari, R., Sansosti, E. (2002). A new algorithm for surface deformation monitoring based on small baseline differential SAR interferograms, IEEE Transactions on Geoscience and Remote Sensing, 40, 2375-2383

[3] Blanco, P., Mallorquí, J.J., Duque, S., Monells, D. (2008). The Coherent Pixels Technique (CPT): an Advanced DInSAR Technique for Non-linear Deformation Monitoring, Pure and Applied Geophysics, 165, 1167-1193

[4] Mulas, J., Aragón, R., Martínez, M., Lambán, J., GarcíaArostegui, J.L., Fernández-Grillo, A.I., Hornero, J., Rodríguez, J., Rodríguez, J.M. (2003). Geotechnical and hydrological analysis of land subsidence in Murcia (Spain). Proc. $1^{a}$ International Conference on Groundwater in Geological Engineering, 22-26 September 2003, Bled, Slovenia, 50, 249-252

[5] T. Roberto, Y. Márquez, J.M. López Sánchez, J. Delgado, P. Blanco, J.J. Mallorquí, M. Martínez, G. Herrera, J. Mulas (2005), Mapping ground subsidence induced by aquifer overexploitation using advanced Differential SAR Interferometry: Vega Media of the Segura River (SE Spain) case study, Elsevier Remote Sensing of Environment, 98, pp. 269-283, August 2005. 